\title{
Genetic diversity, clonality and connectivity in the scleractinian coral Pocillopora damicornis: a multi-scale analysis in an insular, fragmented reef system
} \author{
Mehdi Adjeroud $^{1,2,{ }^{*}}$, Aurélie Guérécheau ${ }^{1}$, Jeremie Vidal-Dupiol ${ }^{3,4}$, Jean-François Flot $^{5}$,
Sophie Arnaud-Haond ${ }^{6}$, François Bonhomme
}

\footnotetext{
${ }^{1}$ Institut de Recherche pour le Développement, Unité 227 CoRéUs2, BP A5, 98848, Nouméa Cedex, New Caledonia

${ }^{2}$ Laboratoire d'Excellence "CORAIL", 58 Avenue Paul Alduy, 66860 Perpignan Cedex, France

${ }^{3}$ CNRS, Ecologie et Evolution des Interactions, UMR 5244, Université de Perpignan Via Domitia, 58 Avenue Paul Alduy, 66860, Perpignan, France

${ }^{4}$ Université de Perpignan Via Domitia, Ecologie et Evolution des Interactions, UMR 5244, 58 Avenue Paul Alduy, 66860, Perpignan, France

5 Max Planck Institute for Dynamics and Self-Organization, Biological Physics and Evolutionary Dynamics, Bunsenstraße 10, 37073, Göttingen, Germany

${ }^{6}$ Ifremer, UMR 212 Ecosystèmes Marins Exploités, Institut Français de Recherche pour l'Exploitation de la Mer, BP 171, 34203, Sète Cedex, France

${ }^{7}$ CNRS, Institut des Sciences de l'Evolution, UMR 5554, Université de Montpellier 2, cc 63, Place Eugène Bataillon, 34095, Montpellier Cedex 5, France
}

*: Corresponding author : edhi Adjeroud, email address : mehdi.adjeroud@ird.fr

\begin{abstract}
:
Clonality and genetic structure of the coral Pocillopora damicornis sensu lato were assessed using five microsatellites in 12 populations from four islands of the Society Archipelago (French Polynesia) sampled in June 2008. The 427 analysed specimens fell into 132 multilocus genotypes (MLGs), suggesting that asexual reproduction plays an important role in the maintenance of these populations. A haploweb analysis of ITS2 sequences of each MLG was consistent with all of them being conspecific. Genetic differentiation was detected both between and within islands, but when a single sample per MLG was included in the analyses, the populations turned out to be nearly panmictic. These observations provide further evidence of the marked variability in reproductive strategies and genetic structure of $P$. damicornis throughout its geographic range; comparison with results previously obtained for the congeneric species Pocillopora meandrina underlines the importance of life history traits in shaping the genetic structure of coral populations.
\end{abstract}

Communicated by C. Riginos. 


\section{Introduction}

Coral reefs are one of the most diverse ecosystems on Earth and provide goods and services to 500 million people (Moberg and Folke 1999; Wilkinson 2008). However, in recent decades coral reefs have been confronted with various types of natural and anthropogenic disturbances, and are expected to be highly vulnerable to future climatic changes (Hughes et al. 2003; Bellwood et al. 2004; Hoegh-Guldberg et al. 2007; Adjeroud et al. 2009; Hoegh-Guldberg 2009). Coral reefs are mostly supported by colonial calcifying organisms, the scleractinian corals, which are also a key component of coral reef health and diversity as they provide a variety of shelter and food for thousands of reef organisms (Lesser 2004; Bellwood et al. 2006). Thus, the recent widespread mortality of coral species in response to large-scale disturbances and chronic stressors has caused important habitat degradation and, in a number of cases, phase shifts in community structure (Gardner et al. 2003; Pandolfi et al. 2003; Bellwood et al. 2004, 2006). Classically, these phase shifts have involved the replacement of scleractinian corals by macroalgae or other non-reef-building benthic organisms, with important consequences for the structure and functioning of coral reef ecosystems (McManus and Polsenberg 2004).

In this context of an ongoing "coral reef crisis" (Bellwood et al. 2004), important efforts have been recently made to conserve and manage coral reefs with, for example, the implementation of Marine Protected Area (MPA) networks (Mora et al. 2006; Almany et al. 2009) $\square$. Such conservation actions largely depend on the knowledge of the key biological and physical factors that govern the structure and dynamics of reef communities. Among these factors, the level of gene flow and the scale of genetic connectivity have been shown to have a large influence on the vulnerability and resilience of coral populations to perturbations, and are thus key parameters for the location, size and spacing of MPAs (Sale et al. 2005; Miller and Ayre 2008; Almany et al. 2009; Botsford et al. 2009; Jones et al. 2009.

In scleractinian corals as in most marine species, the level of connectivity is often impossible to infer from direct observations. Except for some species of brooding corals that release relatively large larvae, the small size of coral propagules and the absence of available structure for tagging them make it impossible to follow dispersing individuals for long distances (Harrison 2011). The pelagic larval duration (PLD) has sometimes been used to estimate the maximum connectivity. However, correlation between PLD and level of gene flow remains elusive for several biological and methodological reasons (Riginos et al. 2011; Selkoe and Toonen 2011; Treml et al. 2012; Faurby and Barber 2012). First, PLDs can be extremely difficult to assess, as it is a plastic life-history trait (Nozawa and Harrison 2008) under strong influence of environmental conditions such as temperature (Duarte 2007; O'Connor et al. 2007). Moreover, most larvae are able to change their vertical positioning in the water column and, together with the complexity of oceanic currents, this behaviour makes it highly difficult to correlate PLD and maximum distance of larval migration (Palumbi 1994; Parsons 1996). Therefore, connectivity among coral populations has been mainly assessed by examination of its indirect effects on their genetic structure and differentiation (Ayre and Hughes 2000; Elmhirst et al. 2009).

Scleractinian corals exhibit a variety of modes of reproductive systems that may directly influence their potential for dispersal and the level of clonality within local populations (Stoddart 1984a, b; Ayre et al. 1997; Ayre and Hughes 2000; Nishikawa et al. 2003; Heyward and Negri 2012; among others). Corals can be hermaphroditic or gonochoric, and brooders or broadcasters (Harrison 2011). Broadcasters are thought to be great dispersers, whereas brooders are considered to be poor dispersers, and have the potential for self-fertilization (Carlon 1999; Ayre and Hughes 2000; Nishikawa et al. 2003; Miller and Ayre 2008; Underwood et al. 2009). These two modes coexist in certain species and may vary across their geographic range (Harrison 2011). Larvae that contain symbiotic dinoflagellates are also thought to disperse farther than aposymbiotic ones as they can obtain energy from their symbionts (Richmond 1987; Harii et al. 2010; Figueiredo et al. 2012). Moreover, asexual reproduction exists in corals in a variety of forms, including fragmentation, budding or polyp expulsion, asexually produced 
planulae and embryo fragmentation (Richmond 1987; Harrison 2011; Heyward and Negri 2012). The relative contributions of sexual and asexual reproduction largely determine the level of clonality within local populations and the pattern of genetic structure and connectivity among metapopulations (Stoddart 1984a, b; Ayre et al. 1997; Ayre and Hughes 2000; Ayre and Miller 2004; Becheler et al. 2010).

The scleractinian coral Pocillopora damicornis sensu lato (following Veron 2000) has one of the largest spatial repartitions of Indo-Pacific corals, and is commonly found in tropical and subtropical regions from the Red Sea and East African coast to the Eastern Pacific (Veron 2000). The taxonomy of $P$. damicornis is presently in a state of flux, with several molecular studies and morphological species suggesting that it is actually composed of cryptic species, some of which sympatric (Richmond and Jokiel 1984; Flot 2007a; Flot et al. 2008; Souter 2010; Pinzón and LaJeunesse 2011; Schmidt-Roach et al. 2013). P. damicornis has been described as a brooder in most studies (Stoddart 1983; Richmond 1987) but as a broadcast-spawner in some populations (Glynn et al. 1991; Combosch and Vollmer 2011; Schmidt-Roach et al. 2012) $\square$. This coral can also release asexually produced planulae (Stoddart 1983; Ayre and Miller 2004; Sherman et al. 2006) and may rely on fragmentation, thus facilitating the persistence of local populations (Richmond 1987; Adjeroud and Tsuchiya 1999). As expected from such a diversity of reproductive strategies, contrasting patterns of genetic differentiation and connectivity have been observed (see Table 3 in Pinzón et al. 2012), ranging from fine-scale genetic subdivision along East African (Souter et al. 2009) $\square$, Southwest Australian (Stoddart 1984a, b; Whitaker 2006) $\square$ and Panaman (Combosch and Vollmer 2011) coasts, to large-scale panmixia on the Great Barrier Reef (Ayre et al. 1997; Ayre and Hughes 2000) $\square$. Clonality levels in $P$. damicornis populations seem also highly variable, with some populations considered highly clonal (Stoddart 1984a, b; Souter 2009; Gorospe and Karl 2013), whereas others exhibit low (Adjeroud and Tsuchiya 1999) or almost no clonality (Benzie et al. 1995; Ayre et al. 1997; Ayre and Miller 2004; Sherman et al. 2006; Combosch and Vollmer 2011).

The aim of the present study was to examine the genetic diversity, clonality and connectivity of $P$. damicornis sensu lato in an insular, fragmented reef system. We chose to focus on populations from the Society Archipelago (French Polynesia) in order to compare our results with those of a similar study conducted previously on $P$. meandrina in the same region (Magalon et al. 2005). As in this previous study, we used a hierarchical sampling design integrating both the regional scale (among four islands) and the local scale (among three sites on each island). $P$. meandrina is abundant on exposed reef fronts and mainly reproduces sexually through broadcast spawning gametes, resulting in a high gene flow and reduced genetic differentiation among regional populations (Magalon et al. 2005). In contrast, $P$. damicornis sensu lato is mainly found in sheltered back reef habitats (Veron 2000) and is able to reproduce asexually, two factors that should result in more clonality and less gene flow compared with $P$. meandrina. Both species are abundant in the Society Islands, which is therefore an ideal place to test the hypothesis of an influence of life-history traits and ecology on the genetic structure of coral populations and on their connectivity.

\section{Material and methods}

\subsection{Sampling}

Populations identified morphologically as $P$. damicornis following Veron and Pichon (1976) were sampled in four islands of the Society Archipelago (Moorea, Raiatea, Taha'a, and Tahiti), French Polynesia (CITES export: FR089800007-E, CITES import: FR089800007-I). In order to integrate the regional and the local scales, a hierarchical sampling design was established, with samples collected from three sites on each of these four islands (Moorea: MH, MP, MT; Raiatea: RA, RT, RU; Taha'a: TaF, TaT, TaV; Tahiti: TP, TT, TV; Fig. 1) in June 2008. Between 25 and 43 coral colonies were sampled at each site (Table 1), for a total of 427 colonies. The collecting sites 
were located on the fringing reef, at approximately $2 \mathrm{~m}$ depth. Colonies were sampled along transect lines with a minimum distance of $2 \mathrm{~m}$ between two sampled colonies to minimize the collection of several ramets per genet (Adjeroud and Tsuchiya 1999; Magalon et al. 2005; PazGarcía et al. 2012). Each sample was obtained by cutting off the tip of a coral branch $(1-2 \mathrm{~cm})$. Fragments were placed in zip-lock plastic bags and held in seawater before being placed in CHAOS buffer (4 M guanidium thiocyanate, $0.5 \% \mathrm{~N}$-lauroyl sarcosine sodium, $25 \mathrm{mM}$ Tris- $\mathrm{HCl}$ $\mathrm{pH}$ 8, $0.1 \mathrm{M}$ 2-mercaptoethanol) modified from Fukami et al. (2004) following Flot (2007a). Samples were then conserved at ambient temperature and protected from light. DNA was purified following a conventional phenol/chloroform (1:1) protocol and precipitated with isopropanol.

\subsection{Genotyping}

Samples were genotyped using five microsatellite markers: PV2, PV7 (Magalon et al. 2004) $\square$, Pd3-002, Pd3-004 and Pd3-005 (Starger et al. 2008), $\square$ previously shown to be coral-specific and polymorphic in $P$. damicornis. The polymorphism of PV2 and PV7 had previously been tested on populations from French Polynesia, whereas Pd3-002, Pd3-004 and Pd3-005 had been tested on populations from Indonesia and Taiwan (Starger et al. 2008). In the present study, intrapopulation and inter-population polymorphism were both checked for each marker using Spreadex® gel electrophoresis (Elchrom Scientific). Two multiplex polymerase chain reactions (PCR) were then performed on each sample using fluorescently labelled primers. The QIAGEN multiplex PCR kit was used with a final volume of $10 \mu \mathrm{L}$, following the microsatellite protocols. The PCR programme included $15 \mathrm{~min}$ at $95^{\circ} \mathrm{C}$ followed by 25 cycles of $30 \mathrm{~s}$ at $94^{\circ} \mathrm{C}, 90 \mathrm{~s}$ at $57^{\circ} \mathrm{C}$ and $60 \mathrm{~s}$ at $72^{\circ} \mathrm{C}$. A final elongation step consisted of $30 \mathrm{~min}$ at $60^{\circ} \mathrm{C}$. Amplified fragments were visualized on an $A B I$ Prism $3130 \mathrm{XL}$ sequencer (Applied Biosystems) using a GeneScan 500-Rox ladder. Genotype calling was performed using GENEMAPPER 4.0 (Applied Biosystems) and each genotype was visually checked.

\subsection{Molecular delimitation of species}

Several studies have reported cryptic diversity within $P$. damicornis sensu lato (Richmond and Jokiel 1984; Flot 2007a; Flot et al. 2008; Souter 2010; Pinzón and LaJeunesse 2011; SchmidtRoach et al. 2013). To rule out a possibly confounding effect of cryptic species on our population genetic analyses, we used the published coral-specific PCR primers ITSc2-5 and R28S1 (Flot and Tillier 2006; Flot et al. 2008) to amplify and sequence the nuclear ITS2 for one representative individual of each MLG. The haplotypes of length-variant heterozygotes were inferred directly from the patterns of double peaks in the forward and reverse chromatograms using the program Champuru (Flot et al. 2006; Flot 2007b); heterozygotes having haplotypes of equal lengths were subsequently phased using the programs SeqPHASE (Flot 2010) and PHASE (Stephens et al. 2001). All haplotype sequences were deposited in GenBank (accession numbers: $X X X X X X-X X X X X X)$; the processed chromatograms (in a Sequencher file) and the haplotype alignment were deposited in dryad (doi: $X X X X X X X$ ). A median-joining haplotype network was constructed using the program Network (Fluxus Technology) and exported as PDF using Network Publisher (from the same company). This haplonet was subsequently imported into Inkscape and turned into a haploweb (Flot et al. 2010) by adding connections between haplotypes found co-occurring in heterozygotes individuals.

\subsection{Dataset preparation}

In order to associate each ramet (i.e., each physical individual colony that was sampled) to its genet (i.e., clonal lineage encompassing all ramets deriving from the same zygote), the genotypic resolution of the five microsatellites analysed here was checked by visualizing in GENCLONE the number of distinct multilocus genotypes (MLGs) detected for all possible 
subsets of loci (Arnaud-Haond and Belkhir 2007). Then, for each repeated MLG, the probability of obtaining the same MLG more than once from distinct random reproductive events was estimated as $\operatorname{psex}\left(\mathrm{F}_{\mathrm{IS}}\right)$ (Arnaud-Haond et al. 2007).

\subsection{Population genetics analyses}

The magnitude and direction of departure from the Hardy-Weinberg Equilibrium (HWE) at each locus were estimated using GENETIX software version 4.05.2 (Belkhir et al. 1996) with 10,000 permutations. These parameters were expressed as Wright's $F_{I S}$, which is the percentage deviation from expected heterozygosity in each population (Wright 1950). In order to estimate clonal richness and heterogeneity in each population, the clonal richness $\mathrm{R}$ was estimated as:

$$
R=\frac{(G-1)}{(N-1)}
$$

where $G$ is the number of MLGs and $N$ the number of ramets sampled (following Arnaud-Haond et al. 2007). This index ranges from 0 (for a monoclonal stand) to 1 (when all the different samples analysed correspond to a single MLG) and provides a lower bound estimate of the clonal vs. sexual input (Arnaud-Haond et al. 2007). In order to test for significant genetic variation among sites, the genetic differentiation between populations was estimated using Weir and Cockerham's $F_{S T}$ estimator $\theta$ (Weir and Cockerham 1984) with 10,000 permutations between samples. However, the differentiation captured by $F_{S T}$ among populations in which both sexual and asexual reproduction occurs can be the result of different clones being dominant in each population. A second data set was obtained by keeping only one sample for each MLG in each population. $F_{S T}$ was then estimated for this data set restricted to colonies of different sexual origins. In order to test for genetic variation within populations, Wright's $F_{\text {IS }}$ at each locus was also estimated for this data set. GENETIX was then used to construct a Correspondence Analysis (CA) to visualize the genetic distance among populations in a multidimensional space. The output of the CA was simplified by plotting only the centroids of all samples within a population.

\section{Results}

\subsection{Species delimitation}

All 23 ITS2 haplotypes in the network were connected through heterozygous individuals, with no obvious departure from panmixia: the most frequent haplotypes (represented by the large circles on Fig. 2) were found co-occurring in many heterozygotes (represented by thick red curves connecting these circles), whereas rare haplotypes were found co-occurring with frequent ones but not with other rare haplotypes. Hence, the 132 individuals sequenced belonged to a single field for recombination sensu Doyle (1995), i.e. were conspecific following the criterion of mutual allelic exclusivity (Flot et al. 2010). Our studied populations shared several haplotypes with $P$. damicornis from Oahu (Flot et al. 2008, analysis not shown), suggesting that the same species is found both in Hawaii and in the Society Archipelago.

\subsection{Genotypic variation}

Table 1 presents the values of genotypic diversity indices calculated for the entire dataset. Six of the 12 populations significantly deviated from Hardy-Weinberg expectations (HWE), as estimated by Wright's $F_{I S}$ (Table 1 ). When analysing single-locus genotypic variation, 43 HardyWeinberg tests (of 72) showed significant deviation from HWE (Online Resource 1). Of these, 32 
showed heterozygote excesses, and the remaining 11 exhibited deficits. Allelic frequencies and allelic richness recorded at the 12 populations are presented in Online Resource 2.

The hypothesis of multiple reproduction events being responsible of the presence of several individuals per MLG was rejected (with $p_{\text {sex }}\left(F_{I S}\right)<0.05$ ) for about half of the repeated MLGs, but not for the other half that included mostly the predominant genotypes in the populations. This could either be due to the lack of power associated with the $p_{\text {sex }}\left(F_{I S}\right)$ estimates in cases of low allelic and low clonal richness, or to the presence of genotypic variation that remained undetected using the set of five loci available. In every population, some MLGs were repeated, indicating that asexual reproduction or fragmentation occurred at all sampling sites. Sixteen MLGs were shared by different samples, of which only 11 were shared by populations from different islands. Six MLGs were shared by Moorea and Tahiti (ca. $30 \mathrm{~km}$ distance), three by Taha'a and Raiatea (ca. $10 \mathrm{~km}$ distance), one by Moorea and Taha'a (ca. $200 \mathrm{~km}$ distance) and one by Moorea, Taha'a and Raiatea. No MLGs were common to Taha'a and Tahiti (ca. $230 \mathrm{~km}$ distance) or to Raiatea and Tahiti (ca. $220 \mathrm{~km}$ distance). However, after removal of all duplicated MLGs, the newly estimated $F_{I S}$ showed no significant departure from HWE. Clonal richness (R) estimated only on the basis of unique MLGs was therefore an underestimate of the genotypic richness potentially present in the sampling sets. However, R was highly variable among locations (Table 1), reaching 0.600 in Moorea (MT) and 0.097 in a population from Raiatea (RU) that was entirely dominated by four MLGs.

\subsection{Genetic differentiation among sampling sites}

Population differentiation was assessed using pairwise $\mathrm{F}_{\mathrm{ST}}$ comparisons (Table 2). On the basis of the entire dataset (including replicates), $F_{S T}$ was always significant $(p<0.01)$ except for two pairs of samples from Moorea (MH/MP and MP/MT). It was highly variable, ranging from 0.019 between Moorea-MP and Moorea-MT to 0.392 between Raiatea-RT and Tahiti-TP. When each MLG was considered only once, a different pattern was obtained. Taha'a-TaF showed significant $\mathrm{F}_{\mathrm{ST}}$ in comparison with two Moorea (MH/MT), two Raiatea (RA/RU), and two Tahiti (TP/TT) samples. Another pair of samples exhibited a significant $F_{S T}$ : Raiatea-RT/Tahiti-TP. $F_{S T}$ ranged between $0.000(\mathrm{MH} / \mathrm{MT})$ and 0.120 for $(\mathrm{TaF} / \mathrm{RU})$.

Correspondence Analyses (CA) were performed in order to illustrate the genetic differences among populations in a multidimensional space (Fig. 3). The three populations from Taha'a were largely dispersed along both axes $1 \& 2$ (Fig. 3a) and axes $1 \& 3$ (Fig. 3b), indicating a higher genetic distance compared to populations from the three other islands. Genetic distance among the Raiatea populations was also much higher than the variability among Moorea or Tahiti populations, for which populations were grouped together in the CA plots (Fig. 3).

\section{Discussion}

\subsection{Asexual reproduction and clonality levels}

Negative $F_{I S}$ values were recorded at each locus in 10 of the 12 populations of Pocillopora damicornis analysed, indicating an excess of heterozygosity compared to the HWE expectation. Such an excess of heterozygotes has previously been interpreted as an effect of clonality (De Meeus and Balloux 2005; Stoeckel et al. 2006): if heterozygotes have better fitness (size, clonal growth rate, survival, etc.), then their clonal propagation will result in their dominance in natural populations. In line with this interpretation, $F_{I S}$ values no longer differed from HWE once the repeated MLGs were excluded from the analysis, confirming that these departures from HWE were probably explained by the frequent occurrence of asexual reproduction and the higher heterozygosity level of highly represented (and therefore probably more widespread) MLGs. Notwithstanding this, the low number of MLGs retained in some populations, with psex $\left(\mathrm{F}_{\mathrm{IS}}\right)$ 
values meaning that it was not possible to determine the clonal identity of all of them, may not provide enough statistical power to detect departures from HWE among sexually-generated colonies. The occurrence of several significantly positive $F_{I S}$ values, indicating a deficit of heterozygotes for some populations and loci, may result from a combination of several other factors such as null alleles and inbreeding (Gaffney et al. 1990; Ayre et al. 1997), or the occurrence of micro-scale Wahlund effects due to genetic patchiness (i.e., the admixture of several differentiated cohorts; Johnson and Black 1984; David et al. 1997; Hedgecock et al. 2007; Arnaud-Haond et al. 2008; Selkoe et al. 2010), potentially accentuated by clonal growth after settlement (Becheler et al. 2010).

Restricted levels of genotypic diversity were observed in our study despite a collection strategy designed to minimize the sampling of replicates of the same clonal lineage. Although the set of markers we used showed a limited power for ascertaining the clonal membership of some of the MLGs, the satisfying level of discrimination obtained for many other MLGs suggests that the low level of genotypic diversity detected here also reflects an important role of asexual reproduction in the effective recruitment of colonies and the maintenance of populations of $P$. damicornis from the Society Islands. These outcomes are comparable with those obtained for $P$. damicornis sensu lato in southwestern Australia (Stoddart 1984a, b; Whitaker 2006), East Africa (Souter et al. 2009), Hawai'i (Gorospe and Karl 2013), and in some islands of the Ryukyu Archipelago (Adjeroud and Tsuchiya 1999). However, they contrast with the predominance of sexual reproduction and high levels of genotypic richness observed in populations of $P$. damicornis from the Great Barrier Reef (Benzie et al. 1995; Ayre et al. 1997), West Papua New-Guinea, Indonesia (Starger et al. 2008), and the Tropical Eastern Pacific (Combosch and Vollmer $2011) \square$. These outcomes highlight the marked geographic variability in the importance of asexual reproduction and clonality levels in $P$. damicornis.

The importance of asexual reproduction sensu lato (i.e., including fragmentation) and the resulting clonality levels that we recorded for $P$. damicornis in the Society Islands $(0.097<$ clonal richness $\mathrm{R}<0.600$ ) also contrast with the higher levels of genotypic richness found in the same region for $P$. meandrina $(0.847<\mathrm{R}<1.000$; Magalon et al. 2005). These differences could be partly explained by the respective reproductive modes of these corals and the environmental conditions of their preferred habitats. In French Polynesia, the brooding $P$. damicornis relies more on asexual reproduction than does the broadcast-spawning $P$. meandrina (Magalon et al. $2005) \square$. Given its shape, clonality in $P$. damicornis may be enhanced by a higher level of fragmentation, even if production of asexual (parthenogenetic) larvae could also explain such a high level of clonality. In the Society Islands, $P$. damicornis is mainly restricted to back reef habitats, with a preference for fringing reefs where it forms abundant populations of delicately branching colonies. This skeletal fragility, in association with the chronic occurrence of perturbations such as trampling, gleaning, fishing and anchoring, probably results in high fragmentation rates associated with important survival of some fragments, possibly leading to high levels of clonality within local populations (Pinzón et al. 2012). The frequent occurrence of $P$. damicornis fragments at our sampling sites ( $M$. Adjeroud, pers. obs.) reinforces the hypothesis of fragmentation as an important mechanism underlying the clonal spread and persistence of local populations. In contrast, $P$. meandrina is mainly found on outer reef slopes, where it forms robust branching colonies. Fragmentation of these colonies is probably less common, occurring mainly during major storms. In any case, the chronically high hydrodynamic forces resulting from the currents, swell and wave actions in this habitat probably do not allow the successful settlement and survival of coral fragments of $P$. meandrina, a combination of factors that may explain the contrasting level of clonal richness with its sister species $P$. damicornis.

\subsection{Genetic differentiation and gene flow}

A significant genetic differentiation was detected at the regional scale among populations of the four islands of the Society Archipelago, and at the island scale among the three populations of 
each island. Some populations sampled on Raitaea and its sister island Taha'a (these two islands share the same lagoon) were clearly differentiated from all other populations. While it is difficult to discern between the various hypotheses that may explain this pattern, the observed genetic differentiation could partly result from two consecutive cyclones that have affected Raiatea, Taha'a and Bora Bora in October (Martin) and November (Osea) 1997 (Adjeroud et al. 2005). The post-disturbance recolonization by coral fragments and by asexually generated propagules from surviving colonies, together with the sexual propagules from nearby, lessdisturbed coral reefs, may explain the high levels of clonality within these populations and their genetic distance compared to other populations in the Society Islands. This mechanism has been suggested for several coral species from other Indo-Pacific coral reefs (Hunter 1993; Sherman et al. 2006; Underwood et al. 2007; Souter et al. 2010; Starger et al. 2010).

The regional-scale genetic differentiation found for $P$. damicornis is quite different from the panmixia observed in the Society Islands for the broadcast spawner $P$. meandrina (Magalon et al. 2005) $\square$. The population structure of $P$. damicornis appears to be largely shaped by the important clonality observed within most of the studied populations. The values of $F_{S T}$ obtained when each multilocus genotype (MLG) was considered only once (e.g., restricting our analysis to colonies of putative sexual origin) reveal that the pattern observed in the Society Islands for $P$. damicornis is not far from panmixia, although for some samples the low number of genotypes may not offer sufficient statistical power to detect a moderate departure from panmixia. As all samples were differentiated based on the entire datasets, and the reduced sample was based on a potentially incomplete set of genetically distinct individuals, it is likely that $F_{S T}$ estimates based on the reduced dataset would lack statistical power and underestimate some of the genetic differentiation occurring at the local scale among the French Polynesian locations.

In conclusion, this study provides further evidence of marked variability in the reproductive strategies and genetic structure of $P$. damicornis throughout its geographic range. Our results clearly demonstrate that asexual reproduction plays a primary role in the maintenance of local populations of $P$. damicornis in the Society Islands, and results in a relatively high level of clonality within populations and significant genetic differentiation among populations. However, when considering only colonies of distinct sexual origin, our results suggest a potentially substantial gene flow among some populations from the Society Islands. These outcomes are in accordance with previous models of dispersal and population maintenance in species with mixed modes of reproduction (Williams 1975; Bell 1982), which postulate that sexually-derived larvae provide long-distance colonists and gene flow between distant populations, whereas asexual reproduction plays a primary role in the maintenance of local populations (Ayre and Willis 1988; Adjeroud and Tsuchiya 1999). However, our results (sharing of MLGs by distant populations) suggest that regional-scale dispersal of asexually produced larvae may also occur, as proposed by Schmidt-Roach et al. (2013) on the Great Barrier Reef. This contrasts with the lower level of clonality previously found for the congeneric species $P$. meandrina at the same study area; hence, our results clearly underline the importance of life-history traits and ecology in shaping the genetic structure of coral populations. However, our hypothesis that $P$. damicornis should exhibit a lower genetic connectivity than $P$. meandrina was not clearly supported by our results. This suggests that, at the spatial scales examined here, high level of clonality within populations is compatible with high genetic connectivity among distant populations.

\section{Acknowledgements}

Some samples were collected with the help of Pauline Bosserelle from the CRIOBE USR 3278 CNRS-EPHE. The samples were genotyped at the IFR 119 "Montpellier Environnement Biodiversité". We would particularly like to thank Marie-Thérèse Augé, Érick Desmarais, Frédérique Cerqueira, and Nicolas Bierne for their help in data acquisition and analysis. This paper is a contribution to the ANR "ADACNI" (ANR-12-ADAP-0016) 
Adjeroud M, Tsuchiya M (1999) Genetic variation and clonal structure in the scleractinian coral Pocillopora damicornis in the Ryukyu Archipelago, southern Japan. Mar Biol 134:753-760

Adjeroud M, Chancerelle Y, Schrimm M, Perez T, Lecchini D, Galzin R, Salvat B (2005) Detecting the effects of natural disturbances on coral assemblages in French Polynesia: a decade survey at multiple scales. Aquat Living Resour 18:111-123

Adjeroud M, Michonneau F, Edmunds PJ, Chancerelle Y, Penin L, Vidal-Dupiol J, Salvat B, Galzin R (2009) Recurrent disturbances, recovery trajectories, and resilience of coral assemblages on a south Central Pacific reef. Coral Reefs 28:775-780

Almany GR, Connolly SR, Heath DD, Hogan JD, Jones GP, McCook LJ, Mills M, Pressey RL, Williamson DH (2009) Connectivity, biodiversity conservation and the design of marine reserve networks for coral reefs. Coral Reefs 28:339-351

Arnaud-Haond S, Belkhir K (2007) GENCLONE: a computer program to analyse genotypic data, test for clonality and describe spatial clonal organization. Mol Ecol Notes 7:15-17

Arnaud-Haond S, Duarte CM, Alberto F, Serrao EA (2007) Standardizing methods to address clonality in population studies. Mol Ecol 16:5115-5139

Arnaud-Haond S, Vonau V, Rouxel C, Bonhomme F, Prou J, Goyard E, Boudry P (2008). Genetic structure at different spatial scales in the pearl oyster (Pinctada margaritifera cumingii) in French Polynesian lagoons: beware of sampling strategy and genetic patchiness. Mar Biol 155:147-157

Ayre DJ, Hughes TP (2000) Genotypic diversity and gene flow in brooding and spawning corals along the Great Barrier Reef, Australia. Evolution 54:1590-1605

Ayre DJ, Miller KJ (2004) Where do clonal coral larvae go? Adult genotypic diversity conflicts with reproductive effort in the brooding coral Pocillopora damicornis. Mar Ecol Prog Ser 277:95-105

Ayre DJ, Willis BL (1988) Population structure in the coral Pavona cactus: clonal genotypes show little phenotypic plasticity. Mar Biol 99:495-505

Ayre DJ, Hughes TP, Standish RJ (1997) Genetic differentiation, reproductive mode, and gene flow in the brooding coral Pocillopora damicornis along the Great Barrier Reef, Australia. Mar Ecol Prog Ser 159:175-187

Becheler R, Diekmann O, Hily C, Moalic Y, Arnaud-Haond S (2010) The concept of population in clonal organisms: mosaics of temporally colonized patches are forming highly diverse meadows of Zostera marina in Brittany. Mol Ecol 19:2394-2407

Belkhir K, Borsa P, Chikhi L, Raufaste N, Bonhomme F (1996) Genetix 4.05, Logiciel sous Windows pour la Génétique des Populations. Laboratoire Génome, Populations, Interactions, CNRS UMR 5000, Université de Montpellier II, Montpellier, France

Bell G (1982) The masterpiece of nature: the evolution and genetics of sexuality. Croon Helm, London

Bellwood DR, Hughes TP, Folke C, Nyström M (2004) Confronting the coral reef crisis. Nature 429:827-833

Bellwood DR, Hoey AS, Ackerman JL, Depczynski M (2006) Coral bleaching, reef fish community phase shifts and the resilience of coral reefs. Global Change Biol 12:15871594

Benzie JAH, Haskell A, Lehman H (1995) Variation in the genetic composition of coral (Pocillopora damicornis and Acropora palifera) populations from different reef habitats. Mar Biol 121:731-739

Botsford LW, White JW, Coffroth MA, Paris CB, Planes S, Shearer TL, Thorrold SR, Jones GP (2009) Connectivity and resilience of coral reef metapopulations in marine protected areas: matching empirical efforts to predictive needs. Coral Reefs 28:327-337

Carlon DB (1999) The evolution of mating systems in tropical reef corals. Trends Ecol Evol 14:491-495 
Chen CA, Chang C-C, Wei NV, Chen C-H, Lein Y-T, Lin H-E, Dai C-F, Wallace CC (2004) Secondary structure and phylogenetic utility of the ribosomal internal transcribed spacer 2 (ITS2) in scleractinian corals. Zool Stud 43:759-771

Combosch DJ, Vollmer SV (2011) Population genetics of an ecosystem-defining reef coral Pocillopora damicornis in the Tropical Eastern Pacific. PloS ONE 6:e21200

David P, Berthou P, Noel P, Jarne P (1997) Patchy recruitment patterns in marine invertebrates: a spatial test of the density-dependent hypothesis in the bivalve Spisula ovalis. Oecologia 111:331-340

De Meeus T, Balloux F (2005) F-statistics of clonal diploids structured in numerous demes. Mol Ecol 14:2695-2702

Doyle JJ (1995) The irrelevance of allele tree topologies for species delimitation, and a nontopological alternative. Syst Bot 20:574-588

Duarte CM (2007) Marine ecology warms up to theory. Trends Ecol Evol 22:332-334

Elmhirst T, Connolly SR, Hughes TP (2009) Connectivity, regime shifts and resilience of coral reefs. Coral Reefs 28:949-957

Faurby S, Barber PH (2012) Theoretical limits to the correlation between pelagic larval duration and population genetic structure. Mol Ecol 21: 3419-3432

Figueiredo J, Baird A, Cohen M, Flot J-F, Kamiki T, Meziane T, Tsuchiya M, Yamasaki H (2012) Ontogenetic change in the lipid and fatty acid composition of scleractinian coral larvae. Coral Reefs 31:613-619

Flot J-F (2007a) Towards a molecular taxonomy of corals of the genus Pocillopora. PhD Thesis, Muséum National d'Histoire Naturelle, Paris

Flot J-F (2007b) Champuru 1.0: a computer software for unraveling mixtures of two DNA sequences of unequal lengths. Mol Ecol Notes 7:974-977

Flot J-F, Tillier S (2006) Molecular phylogeny and systematics of the scleractinian coral genus Pocillopora in Hawaii. Proc $10^{\text {th }}$ Int Coral Reef Symp 1:24-29

Flot J-F, Tillier S (2007) The mitochondrial genome of Pocillopora (Cnidaria: Scleractinia) contains two variable regions: the putative D-loop and a novel ORF of unknown function. Gene 401:80-87

Flot J-F, Tillier A, Samadi S, Tillier S (2006) Phase determination from direct sequencing of length-variable DNA regions. Mol Ecol Notes 6:627-630

Flot J-F, Magalon H, Cruaud C, Couloux A, Tillier S (2008) Patterns of genetic structure among Hawaiian corals of the genus Pocillopora yield clusters of individuals that are compatible with morphology. CR Biol 331:239-247

Flot J-F, Couloux A, Tillier S (2010) Haplowebs as a graphical tool for delimiting species: a revival of Doyle's "field for recombination" approach and its application to the coral genus Pocillopora in Clipperton. BMC Evol Biol 10:372

Flot J-F (2010) SeqPHASE: a web tool for interconverting PHASE input/output files and FASTA sequence alignments. Mol Ecol Resources 10: 162-166

Fukami H, Budd AF, Levitan DR, Jara J, Kersanach R, Knowlton N (2004) Geographic differences in species boundaries among members of the Montastraea annularis complex based on molecular and morphological markers. Evolution 38:324-337

Gaffney PM, Scott TM, Koehn RK, Diehl WJ (1990) Interrelationships of heterozygosity, growth rate and heterozygote deficiencies in the coot clam, Mulina lateralis. Genetics 124:687699

Gardner TA, Côté IM, Gill JA, Grant A, Watkinson AR (2003) Long-term region-wide declines in Caribbean corals. Science 301:958-960

Glynn PW, Gassman NJ, Eakin CM, Cortes J, Smith DB, Guzman HM (1991) Reef coral reproduction in the eastern Pacific: Costa Rica, Panama, and Galapagos Islands (Ecuador). I. Pocilloporidae. Mar Biol 109:355-368

Gorospe KD, Karl SA (2013) Genetic relatedness does not retain spatial pattern across multiple spatial scales: dispersal and colonization in the coral, Pocillopora damicornis. Mol Ecol doi: 10.1111/mec.12335

Harii S, Yamamoto M, Hoegh-Guldberg O (2010) The relative contribution of dinoflagellate photosynthesis and stored lipids to the survivorship of symbiotic larvae of the reef-building corals. Mar Biol 157:1215-1224 
Harrison PL (2011) Sexual reproduction of scleractinian corals. In: Dubinsky Z, Stambler N (eds), Coral reefs: an ecosystem in transition, Part 3. Springer Science+Business Media, pp 59-85

Hedgecock D, Barber PH, Edmands S (2007) Genetic approaches to measuring connectivity. Oceanography 20:70-79

Heyward AJ, Negri AP (2012) Turbulence, cleavage, and the naked embryo: a case for coral clones. Science 335:1064

Hoegh-Guldberg O (2009) Climate change and coral reefs: Trojan horse or false prophecy? Coral Reefs 28:569-575

Hoegh-Guldberg O, Mumby PJ, Hooten AJ, Steneck RS, Greenfield P, Gomez E, Harvell CD, Sale PF, Edwards AJ, Caldeira K, Knowlton N, Eakin CM, Iglesias-Prieto R, Muthiga N, Bradbury RH, Dubi A, Hatziolos ME (2007) Coral reefs under rapid climate change and ocean acidification. Science 318:1737-1742

Hughes TP, Baird AH, Bellwood DR, Card M, Connolly SR, Folke C, Grosberg R, HoeghGuldberg O, Jackson JBC, Kleypas J, Lough JM, Marshall P, Nyström M, Palumbi SR, Pandolfi JM, Rosen B, Roughgarden J (2003) Climate change, human impacts, and the resilience of coral reefs. Science 301:929-933

Hunter CL (1993) Genotypic variation and clonal structure in coral populations with different disturbance histories. Evolution 47:1213-1228

Johnson MS, Black R (1984) Pattern beneath the chaos: the effect of recruitment on genetic patchiness in an intertidal limpet. Evolution 38:1371-1383

Jones GP, Almany GR, Russ GR, Sale PF, Steneck RS, van Oppen MJH, Willis BL (2009) Larval retention and connectivity among populations of corals and reef fishes: history, advances and challenges. Coral Reefs 28:307-325

Lesser MP (2004) Experimental biology of coral reef ecosystems. J Exp Mar Biol Ecol 300:217252

Magalon H, Samadi S, Richard M, Adjeroud M, Veuille M (2004) Development of coral and zooxanthella-specific microsatellites in three species of Pocillopora (Cnidaria, Scleractinia) from French Polynesia. Mol Ecol Notes 4:206-208

Magalon H, Adjeroud M, Veuille M (2005) Patterns of genetic variation do not correlate with geographical distance in the reef-building coral Pocillopora meandrina in the South Pacific. Mol Ecol 14:1861-1868

McManus JW, Polsenberg JF (2004) Coral-algal phase shifts on coral reefs: ecological and environmental aspects. Prog Oceanogr 60:263-279

Miller KJ, Ayre DJ (2008) Protection of genetic diversity and maintenance of connectivity among reef corals within marine protected areas. Conserv Biol 22:1245-54

Moberg F, Folke C (1999) Ecological goods and services of coral reef ecosystems. Ecol Econ 29:215-233

Mora C, Andréfouët S, Costello MJ, Kranenburg C, Rollo A, Veron J, Gaston KJ, Myers RA (2006) Coral reefs and the global network of marine protected areas. Science 312:17501751

Nishikawa A, Katoh M, Sakai K (2003) Larval settlement rates and gene flow of broadcastspawning (Acropora tenuis) and planula-brooding (Stylophora pistillata) corals. Mar Ecol Prog Ser 256:87-97

Nozawa Y, Harrison PL (2008) Temporal patterns of larval settlement and survivorship of two broadcast-spawning acroporid corals. Mar Biol 155:347-351

O'Connor MI, Bruno JF, Gaines SD, Halpern BS, Lester SE, Kinlan BP, Weiss JM (2007) Temperature control of larval dispersal and the implications for marine ecology, evolution, and conservation. P Natl Acad Sci USA 104:1266-1271

Palumbi SR (1994) Genetic divergence, reproductive isolation, and marine speciation. Annu Rev Ecol Evol S 25:547-572

Pandolfi JM, Bradbury RH, Sala E, Hughes TH, Bjorndal KA, Cooke RG, McArdle D, McClenachan L, Newman MJH, Paredes G, Warner RR, Jackson JBC (2003) Global trajectories of the long-term decline of coral reef ecosystems. Science 301:955-958

Parsons KE (1996) The genetic effects of larval dispersal depend on spatial scale and habitat characteristics. Mar Biol 126:403-414 
Paz-García DA, Chávez-Romo HE, Correa-Sandoval F, Reyes-Bonilla H, López-Perez A, Medina-Rosas P, Hernández-Cortés MP (2012) Genetic connectivity patterns of corals Pocillopora damicornis and Porites panamensis (Anthozoa: Scleractinia) along the west coast of Mexico. Pac Sci 66: 43-61

Pinzón JH, LaJeunesse TC (2011) Species delimitation of common reef corals in the genus Pocillopora using nucleotide sequence phylogenies, population genetics and symbiosis ecology. Mol Ecol 20:311-325

Pinzón JH, Reyes-Bonilla H, Baums IB, LaJeunesse TC (2012) Contrasting clonal structure among Pocillopora (Scleractinia) communities at two environmentally distinct sites in the Gulf of California. Coral Reefs 31: 765-777

Richmond RH (1987) Energetics, competency, and long-distance dispersal of planula larvae of the coral Pocillopora damicornis. Mar Biol 93:527-533

Richmond RH, Jokiel PL (1984) Lunar periodicity in larva release in the reef coral Pocillopora damicornis at Enewetak and Hawaii. B Mar Sci 34:280-287

Riginos C, Douglas KE, Jin Y, Shanahan DF, Treml EA (2011) Effects of geography and life history traits on genetic differentiation in benthic marine fishes. Ecography 34: 566-575

Sale PF, Cowen RK, Danilowicz BS, Jones GP, Kritzer JP, Lindeman KC, Planes S, Polunin NVC, Russ GR, Sadovy YJ, Steneck RS (2005) Critical science gaps impede use of notake fishery reserves. Trends Ecol Evol 20:74-80

Schmidt-Roach S, Miller KJ, Woolsey E, Gerlach G, Baird AH (2012) Broadcast spawning by Pocillopora species on the Great Barrier Reef. PLoS ONE 7(12): e50847

Schmidt-Roach S, Lundgren P, Miller K, Gerlach G, Noreen A, Andreakis N (2013) Assessing hidden species diversity in the coral Pocillopora damicornis from Eastern Australia. Coral Reefs 32: 161-172

Selkoe KA, Toonen RJ (2011) Marine connectivity: a new look at pelagic larval duration and genetic metrics of dispersal. Mar Ecol Prog Ser 436: 291-305

Selkoe KA, Watson JR, White C, Ben Horin T, lachhei M, Mitarai S, Siegel DA, Gaines SD, Toonen RJ (2010) Taking the chaos out of genetic patchiness: seascape genetics reveals ecological and oceanographic drivers of genetic patterns in three temperate reef species. Mol Ecol 19: 708-3726

Sherman CDH, Ayre DJ, Miller KJ (2006) Asexual reproduction does not produce clonal populations of the brooding coral Pocillopora damicornis on the Great Barrier Reef, Australia. Coral Reefs 25:7-18

Souter $\mathrm{P}$ (2010) Hidden genetic diversity in a key model species of coral. Mar Biol 157:875-885

Souter P, Henriksson O, Olsson N, Grahn M (2009) Patterns of genetic structuring in the coral Pocillopora damicornis on reefs in East Africa. BMC Ecol 9:19

Souter P, Willis BL, Bray LK, Caley MJ, Muirhead A, van Oppen MJH (2010) Location and disturbance affect population genetic structure in four coral species of the genus Acropora on the Great Barrier Reef. Mar Ecol Prog Ser 416:35-45

Starger CJ, Yeoh SSR, Dai CF, Baker AC, Desalle R (2008) Ten polymorphic STR loci in the cosmopolitan reef coral, Pocillopora damicornis. Mol Ecol Resour 8:619-621

Starger CJ, Barber PH, Ambariyanto, Baker AC (2010) The recovery of coral genetic diversity in the Sunda Strait following the 1883 eruption of Krakatau. Coral Reefs 29:547-565

Stephens M, Smith NJ, Donnelly P (2001) A new statistical method for haplotype reconstruction from population data. Am J Hum Genet 68: 978-989

Stoddart JA (1983) Asexual production of planulae in the coral Pocillopora damicornis. Mar Biol $76: 279-284$

Stoddart JA (1984a) Genetic structure within populations of the coral Pocillopora damicornis. Mar Biol 81:19-30

Stoddart JA (1984b) Genetic differentiation amongst populations of the coral Pocillopora damicornis of southwestern Australia. Coral Reefs 3:149-156

Stoeckel S, Grange J, Fernández-Manjarres JF, Bilger I, Frascaria-Lacoste N, Mariette S (2006) Heterozygote excess in a self-incompatible and partially clonal forest tree species - Prunus avium L. Mol Ecol 15:2109-2118 
Treml EA, Roberts JJ, Chao Y, Halpin PN, Possingham HP, Riginos C (2012) Reproductive output and duration of the pelagic larval stage determine seascape-wide connectivity of marine populations. Integr Comp Biol 52:525-537

Underwood JN, Smith LD, van Oppen MJH, Gilmour JP (2007) Multiple scales of genetic connectivity in a brooding coral on isolated reefs following catastrophic bleaching. Mol Ecol 16:771-784

Underwood JN, Smith LD, van Oppen MJH, Gilmour JP (2009) Ecologically relevant dispersal of corals on isolated reefs: implications for managing resilience. Ecol Appl 19:18-29

Veron JEN (2000) Corals of the world. The Australian Institute of Marine Science, Townsville

Veron JEN, Pichon M (1976) Scleractinia of Eastern Australia Part I. Australian Institute of Marine Science, Canberra

Weir B, Cockerham CC (1984) Estimating F-statistics for the analysis of population structure. Evolution 38:1358-1370

Whitaker K (2006) Genetic evidence for mixed modes of reproduction in the coral Pocillopora damicornis and its effect on population structure. Mar Ecol Prog Ser 306:115-124

Wilkinson C (2008) Status of coral reefs of the world: 2008. Global Coral Reef Monitoring Network and Reef and Rainforest Research Center, Townsville, Australia

Williams GC (1975) Sex and evolution. Princeton University Press, Princeton

Wright S (1950) Genetical structure of populations. Nature 166:247-249

\section{Tables}

Table 1 : Indices of genotypic diversity

\begin{tabular}{lcccccc}
\hline & $N$ & $G$ & $R$ & $H o$ & $H e$ & $F_{I S}$ \\
\hline MH & 30 & 12 & 0.379 & $0.473(0.296)$ & $0.495(0.128)$ & 0.045 \\
MP & 30 & 17 & 0.552 & $0.547(0.122)$ & $0.531(0.082)$ & -0.030 \\
MT & 31 & 19 & 0.600 & $0.652(0.143)$ & $0.534(0.042)$ & $-0.225 * *$ \\
RA & 31 & 10 & 0.300 & $0.594(0.205)$ & $0.568(0.073)$ & -0.047 \\
RT & 25 & 5 & 0.167 & $0.256(0.207)$ & $0.253(0.146)$ & -0.013 \\
RU & 32 & 4 & 0.097 & $0.663(0.262)$ & $0.459(0.121)$ & $-0.453 * *$ \\
TaF & 42 & 16 & 0.366 & $0.610(0.311)$ & $0.477(0.171)$ & $-0.281 * *$ \\
TaT & 43 & 6 & 0.119 & $0.651(0.307)$ & $0.492(0.168)$ & $-0.327 * *$ \\
TaV & 43 & 17 & 0.381 & $0.465(0.187)$ & $0.503(0.152)$ & 0.076 \\
TP & 41 & 17 & 0.400 & $0.556(0.293)$ & $0.506(0.185)$ & -0.100 \\
TT & 40 & 9 & 0.205 & $0.690(0.275)$ & $0.533(0.066)$ & $-0.299 *$ \\
TV & 39 & 20 & 0.500 & $0.646(0.078)$ & $0.578(0.067)$ & $-0.120 *$ \\
\hline
\end{tabular}

$\mathrm{N}$ : sample size; G: number of MLGs; R: clonal richness; Ho: observed heterozygosity ( \pm SD); He: expected heterozygosity $( \pm S D)$; departures from Hardy-Weinberg equilibrium are expressed as $F_{I S}$. Negative values indicate an excess of heterozygotes, and positive values a deficit of heterozygotes. ${ }^{*} p<0.1 ;{ }^{* *} p<0.01$ 
Table 2 : Genetic differentiation between populations

\begin{tabular}{|c|c|c|c|c|c|c|c|c|c|c|c|c|}
\hline & $\mathrm{MH}$ & MP & MT & RA & RT & $\mathrm{RU}$ & $\mathrm{TaF}$ & TaT & $\mathrm{TaV}$ & TP & TT & TV \\
\hline $\mathrm{MH}$ & & 0.036 & $0.041^{*}$ & 0.030 * & $0.335^{*}$ & $0.082^{*}$ & $0.197^{\star}$ & $0.126^{*}$ & $0.078^{*}$ & $0.028^{*}$ & $0.082^{*}$ & $0.081^{*}$ \\
\hline MP & 0.028 & & 0.019 & $0.048^{*}$ & 0.2 & & & & & & & $0.069^{*}$ \\
\hline $\mathrm{MT}$ & 0.000 & 0.013 & & $0.038^{*}$ & $0.213^{*}$ & $0.068^{*}$ & $0.122^{*}$ & $0.070^{*}$ & $0.082^{*}$ & $0.077^{*}$ & $0.059^{\star}$ & $0.041^{*}$ \\
\hline $\mathrm{RA}$ & -0.001 & 0.023 & -0.004 & & $0.289^{*}$ & $0.262^{*}$ & $0.189^{*}$ & 0.1 & $0.309^{*}$ & $0.049^{*}$ & $0.326^{*}$ & $0.058^{*}$ \\
\hline $\mathrm{RT}$ & 0.112 & 0.026 & 0.063 & 0.079 & & $0.274^{*}$ & $0.201^{*}$ & $0.199^{*}$ & $0.324^{*}$ & $0.392^{*}$ & $0.343^{*}$ & $0.273^{*}$ \\
\hline $\mathrm{RU}$ & -0.022 & -0.007 & -0.007 & -0.045 & 0.053 & & $0.145^{*}$ & $0.115^{*}$ & $0.167^{*}$ & 0.1 & 0.1 & $0.132^{*}$ \\
\hline $\mathrm{TaF}$ & $0.101^{*}$ & 0.033 & $0.052^{*}$ & $0.080^{*}$ & 0.047 & $0.120^{*}$ & & $0.092^{*}$ & $0.276^{*}$ & $0.206^{*}$ & $0.214^{*}$ & $0.167^{*}$ \\
\hline TaT & & 0.006 & -0.004 & -0.007 & 0.056 & 0.032 & 0.006 & & $0.217^{*}$ & 0 . & 0 . & 0. \\
\hline $\mathrm{TaV}$ & -0.001 & 0.018 & -0.017 & -0.014 & 0.064 & -0.016 & 0.052 & 0.004 & & $0.123^{*}$ & 0.0 & $0.062^{*}$ \\
\hline $\mathrm{TP}$ & 0.019 & 0.057 & 0.017 & 0.07 & $0.115^{*}$ & 0.056 & $0.067^{*}$ & 0.008 & 0.010 & & $0.059^{*}$ & $0.100^{*}$ \\
\hline $\mathrm{TT}$ & 0.011 & 0.072 & 0.020 & 0.001 & 0.090 & 0.038 & $0.050^{*}$ & 0.050 & -0.002 & 0.010 & & $0.031^{*}$ \\
\hline TV & -0.010 & 0.016 & -0.009 & -0.012 & 0.068 & -0.016 & 0.064 & 0.025 & -0.021 & 0.012 & -0.004 & \\
\hline
\end{tabular}

The estimator is Weir and Cockerham's $\mathrm{F}_{\mathrm{ST}}$. Values above the diagonal were calculated on the complete data set (i.e., colonies of both sexual and asexual origin). Values under the diagonal were calculated on a data set where only one of each MLG had been retained (i.e., colonies of sexual origin). ${ }^{*} p<0.01$ 
Fig. 1 Map of the Society Archipelago in French Polynesia showing the location of the four studied islands (a), and of the 12 sampling sites, in Taha'a and Raiatea (b), and in Moorea and Tahiti (c)

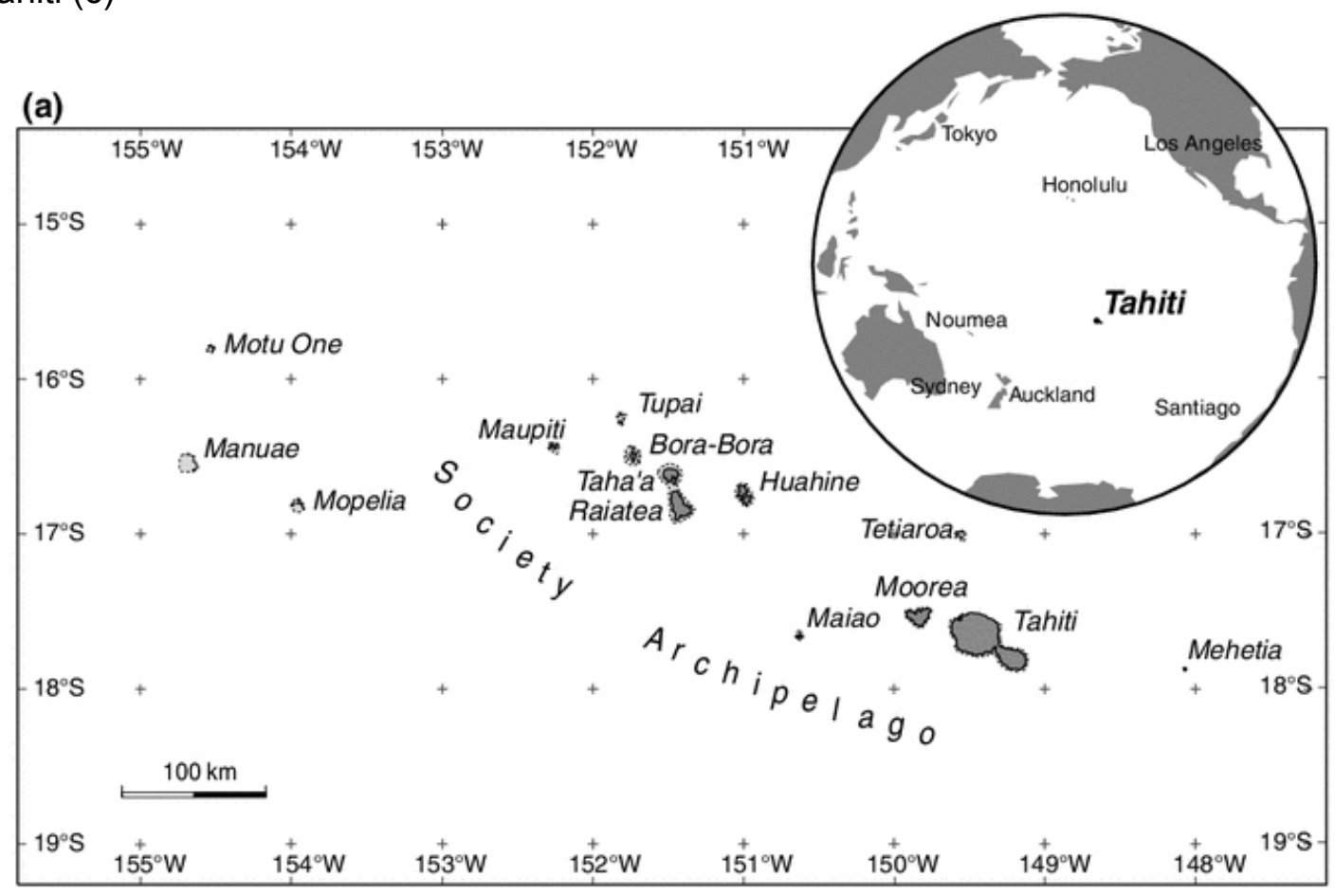

(b)

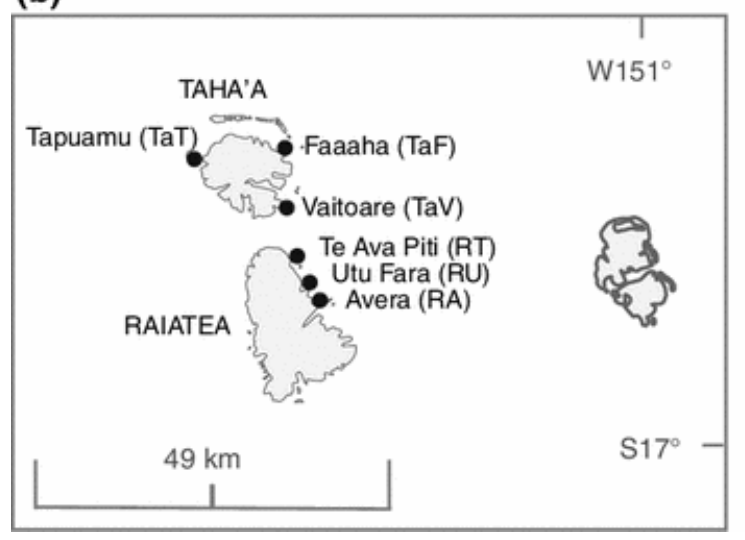

(c)

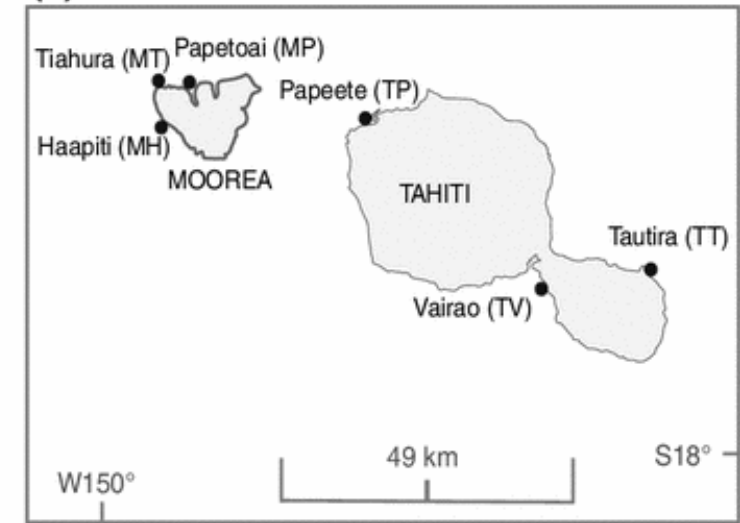


Fig. 2 Haplotype web (haploweb) of ITS2 sequences. Each pie represents one ITS2 type (with its area proportional to the number of individuals in which it was detected, see scale on the left), with the following colour code: Tahaa (Ta) in light blue, Raiatea (R) in dark blue, Moorea (M) in orange, and Tahiti ( $T$ ) in red. The lengths of the grey lines connecting the ITS2 types are proportional to the number of mutations separating them, whereas ITS2 types found cooccurring in heterozygous individuals are connected with red curves (the thickness of which is proportional to the number of heterozygotes in which a given pair of ITS2 types co-occur). Since all ITS2 types are connected by heterozygotes they belong to a single gene pool sensu Doyle (1995), and therefore all individuals sequenced are conspecific following the criterion of mutual allelic exclusivity (Flot et al. 2010)

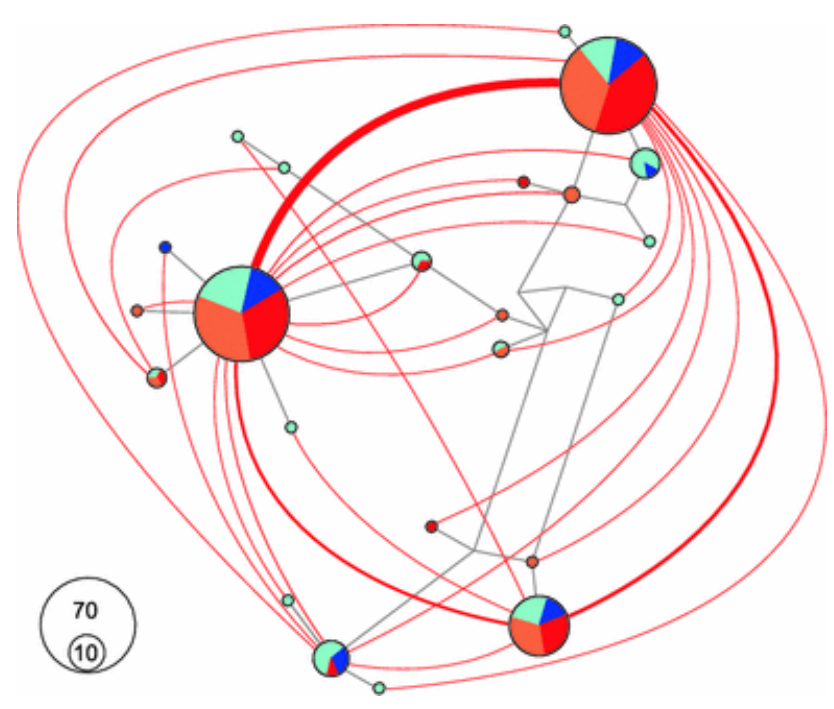


Fig. 3 Genetic distance between populations. Correspondence Analysis conducted on the 12 populations sampled on the four islands in the Society Archipelago. Plots of stations along axes $1 \& 2$ (a), and along axes $1 \& 3$ (b). The percentage of variance (inertia) of each of the first three axes is given

(a)

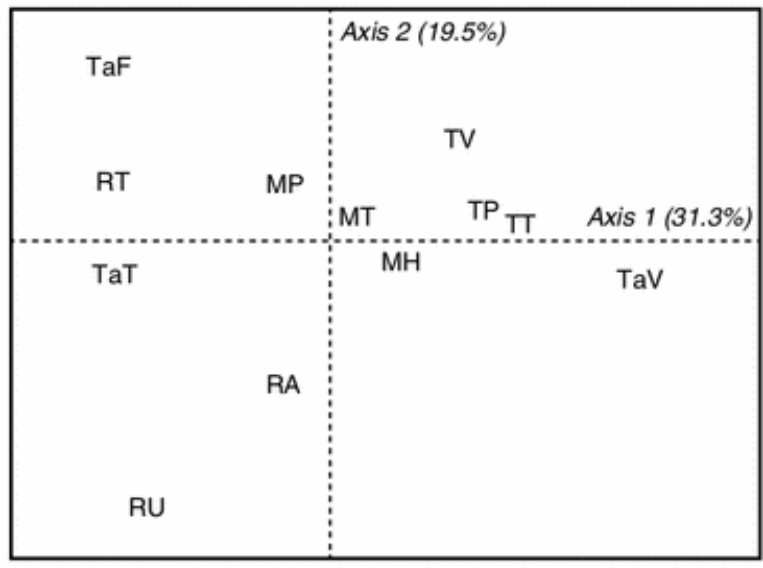

(b)

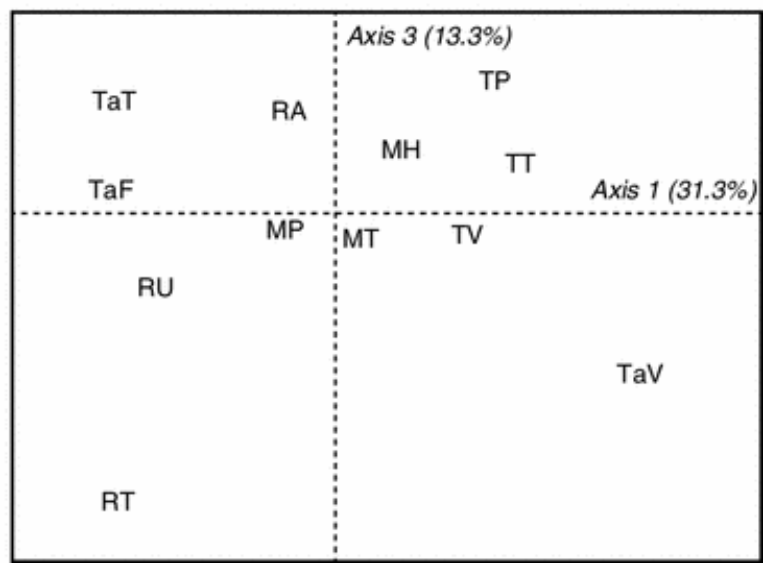




\section{Supplementary material}

Online Resource 1 Departures from Hardy-Weinberg equilibrium expressed as $F_{\text {IS }}$. Negative values indicate an excess of heterozygotes, and positive values a deficit of heterozygotes. ${ }^{*} p<0.1 ;{ }^{* *} p<0.01$

\begin{tabular}{lcccccc}
\hline & All loci & Pd3-002 & PV2 & Pd3-004 & Pd3-005 & PV7 \\
\hline MH & 0.045 & 0.047 & $0.567^{* *}$ & $-0.456 * *$ & 0.029 & $0.275^{*}$ \\
MP & -0.030 & -0.091 & $0.201^{*}$ & -0.053 & $-0.250^{*}$ & 0.043 \\
MT & $-0.225^{* *}$ & $-0.357^{* *}$ & $-0.258^{*}$ & 0.170 & $-0.283^{*}$ & $-0.371^{*}$ \\
RA & -0.047 & $-0.537^{* *}$ & $-0.242^{*}$ & $0.423^{* *}$ & $-0.204^{*}$ & $0.241^{*}$ \\
RT & -0.013 & -0.043 & -0.138 & $0.374 * *$ & $-0.263^{*}$ & $0.472^{* *}$ \\
RU & $-0.453^{* *}$ & $-0.333^{*}$ & $-0.425^{* *}$ & -0.151 & $-0.265^{*}$ & $-0.938^{* *}$ \\
TaF & $-0.281^{* *}$ & $-0.435^{* *}$ & $0.281^{*}$ & -0.141 & $-0.224^{*}$ & $-0.563 * *$ \\
TaT & $-0.327^{* *}$ & $-0.568^{* *}$ & $-0.563^{* *}$ & 0.142 & $-0.333^{* *}$ & -0.120 \\
TaV & 0.076 & 0.021 & $0.268^{*}$ & 0.024 & $0.231 *$ & -0.050 \\
TP & -0.100 & $0.528^{*}$ & $-0.568^{* *}$ & $-0.251 * *$ & 0.195 & -0.062 \\
TT & $-0.299^{* *}$ & -0.048 & 0.117 & $-0.650 * *$ & $-0.667 * *$ & -0.089 \\
TV & $-0.120 *$ & 0.069 & -0.114 & -0.179 & $-0.252 *$ & $-0.147 *$ \\
\hline
\end{tabular}


Online Resource 2 Allelic frequencies at each locus recorded at the 12 populations. A: total number of alleles

\begin{tabular}{|c|c|c|c|c|c|c|c|c|c|c|c|c|}
\hline & $\mathrm{MH}$ & MP & MT & RA & RT & $R U$ & $\mathrm{TaF}$ & TaT & $\mathrm{TaV}$ & TP & TT & TV \\
\hline \multicolumn{13}{|c|}{ Pd3-002 } \\
\hline 185 & 0.733 & 0.566 & 0.516 & 0.581 & 0.060 & 0.672 & 0.512 & 0.535 & 0.267 & 0.890 & 0.575 & 0.359 \\
\hline 189 & 0 & 0.050 & 0 & 0 & 0 & 0 & 0.012 & 0 & 0.256 & 0.036 & 0.025 & 0.012 \\
\hline 191 & 0 & 0 & 0 & 0 & 0 & 0 & 0 & 0 & 0.012 & 0.024 & 0 & 0.166 \\
\hline 199 & 0.050 & 0.066 & 0.080 & 0 & 0 & 0 & 0.060 & 0.035 & 0 & 0 & 0.013 & 0.025 \\
\hline 201 & 0.216 & 0.316 & 0.403 & 0.339 & 0.940 & 0.328 & 0.345 & 0.337 & 0.453 & 0.048 & 0.388 & 0.436 \\
\hline 205 & 0 & 0 & 0 & 0.081 & 0 & 0 & 0.071 & 0.093 & 0.012 & 0 & 0 & 0 \\
\hline A & 3 & 4 & 3 & 3 & 2 & 2 & 5 & 4 & 5 & 4 & 4 & 5 \\
\hline \multicolumn{13}{|l|}{ PV2 } \\
\hline 130 & 0 & 0 & 0 & 0 & 0 & 0 & 0 & 0 & 0 & 0 & 0 & 0.012 \\
\hline 132 & 0.250 & 0.433 & 0.403 & 0.306 & 0.660 & 0.453 & 0.821 & 0.488 & 0.221 & 0.365 & 0.388 & 0.333 \\
\hline 161 & 0.750 & 0.566 & 0.596 & 0.645 & 0.340 & 0.359 & 0.179 & 0.477 & 0.779 & 0.634 & 0.613 & 0.641 \\
\hline 165 & 0 & 0 & 0 & 0.048 & 0 & 0.188 & 0 & 0.035 & 0 & 0 & 0 & 0 \\
\hline A & 2 & 2 & 2 & 3 & 2 & 3 & 2 & 3 & 2 & 2 & 2 & 3 \\
\hline \multicolumn{13}{|c|}{ Pd3-004 } \\
\hline 157 & 0.100 & 0 & 0.032 & 0 & 0.040 & 0 & 0 & 0 & 0 & 0.036 & 0.037 & 0 \\
\hline 160 & 0 & 0 & 0 & 0.113 & 0.040 & 0.203 & 0 & 0 & 0 & 0 & 0 & 0 \\
\hline 161 & 0.166 & 0.100 & 0.177 & 0 & 0 & 0 & 0.047 & 0.081 & 0.267 & 0.231 & 0.087 & 0.064 \\
\hline 163 & 0.500 & 0.750 & 0.677 & 0.419 & 0.900 & 0.781 & 0.833 & 0.698 & 0.384 & 0.341 & 0.387 & 0.602 \\
\hline 166 & 0 & 0 & 0 & 0.081 & 0 & 0 & 0 & 0.093 & 0 & 0 & 0 & 0.012 \\
\hline 169 & 0.233 & 0.150 & 0.113 & 0.387 & 0.020 & 0.016 & 0.119 & 0.128 & 0.349 & 0.390 & 0.488 & 0.307 \\
\hline 175 & 0 & 0 & 0 & 0 & 0 & 0 & 0 & 0 & 0 & 0 & 0 & 0.013 \\
\hline A & 4 & 3 & 4 & 4 & 4 & 3 & 3 & 4 & 3 & 4 & 4 & 5 \\
\hline \multicolumn{13}{|c|}{ Pd3-005 } \\
\hline 199 & 0 & 0 & 0 & 0 & 0 & 0 & 0 & 0 & 0 & 0 & 0 & 0.013 \\
\hline 212 & 0.750 & 0.633 & 0.548 & 0.516 & 0.780 & 0.781 & 0.477 & 0.419 & 0.756 & 0.573 & 0.412 & 0.474 \\
\hline 215 & 0.150 & 0.233 & 0.113 & 0.306 & 0 & 0.219 & 0.274 & 0.419 & 0.047 & 0.134 & 0.100 & 0.089 \\
\hline 218 & 0.100 & 0.133 & 0.339 & 0.177 & 0.220 & 0 & 0.250 & 0.163 & 0.198 & 0.293 & 0.488 & 0.423 \\
\hline A & 3 & 3 & 3 & 3 & 2 & 2 & 3 & 3 & 3 & 3 & 3 & 4 \\
\hline \multicolumn{13}{|l|}{ PV7 } \\
\hline 225 & 0.450 & 0516 & 0.532 & 0.516 & 0.920 & 0.484 & 0.559 & 0.884 & 0.302 & 0.414 & 0.300 & 0.192 \\
\hline 229 & 0.100 & 0.233 & 0.016 & 0 & 0.080 & 0 & 0.393 & 0 & 0.012 & 0.109 & 0.025 & 0.218 \\
\hline 232 & 0 & 0 & 0 & 0 & 0 & 0 & 0 & 0 & 0 & 0 & 0 & 0.025 \\
\hline 234 & 0.450 & 0.250 & 0.452 & 0.484 & 0 & 0.516 & 0.047 & 0.116 & 0.686 & 0.476 & 0.675 & 0.564 \\
\hline$A$ & 3 & 3 & 3 & 2 & 2 & 2 & 3 & 2 & 3 & 3 & 3 & 4 \\
\hline
\end{tabular}

